\title{
Diabetes and exercise
}

\author{
N S Peirce
}

\begin{abstract}
Exercise is frequently recommended in the management of type 1 and 2 diabetes mellitus and can improve glucose uptake by increasing insulin sensitivity and lowering body adiposity. Both alone and when combined with diet and drug therapy, physical activity can result in improvements in glycaemic control in type 2 diabetes. In addition, exercise can also help to prevent the onset of type 2 diabetes, in particular in those at higher risk, and has an important role in reducing the significant worldwide burden of this type of diabetes. Recent studies have improved our understanding of the acute and long term physiological benefits of physical activity, although the precise duration, intensity, and type of exercise have yet to be fully elucidated. However, in type 1 diabetes, the expected improvements in glycaemic control with exercise have not been clearly established. Instead significant physical and psychological benefits of exercise can be achieved while careful education, screening, and planning allow the metabolic, microvascular, and macrovascular risks to be predicted and diminished.
\end{abstract}

(Br F Sports Med 1999;33:161-173)

Keywords: diabetes; exercise; glucose; insulin; glycaemic control

The possible hypoglycaemic benefits of physical activity were originally observed by Aristotle, and later re-advocated as a mainstay of treatment by Allen and Joslin, in the early 1920s. Now widely considered as one of the three main cornerstones of diabetes management, there still remains relatively little guidance for the exercising diabetic. This is despite increasing evidence that many aspects of diabetes can be improved and possibly prevented by regular exercise. At present there are no United Kingdom recommendations for screening, exercise protocols, or treatment regimens, and the personal experience of many with diabetes, including elite athletes, has included frustration and a lack of support on issues of insulin dosage, nutrition, and the potential limits on performance and safety. This review aims to highlight the literature available, while examining the underlying physiology of exercise in diabetes, the benefits and risks of exercise, the strategies for minimising complications, and the potential limitations. The risks and strategies for the distinct population groups represented by type 1 and type 2 diabetes will be looked at separately.
Methods

This review was sourced through searches of Medline, BIDS, and SportDiscus from 1966 to 1998, using the terms type 1 and 2 diabetes mellitus, impaired glucose tolerance, noninsulin and insulin dependent diabetes, insulin sensitivity, exercise, and physical activity. Cross referencing was undertaken and the opinions of diabetologists and athletes on diabetes and exercise were considered.

\section{Classification of diabetes mellitus}

Diabetes is a group of chronic metabolic disorders characterised by hyperglycaemia resulting from a relative deficiency in insulin through either reduced insulin secretion or reduced insulin action or both. The subsequent chronic hyperglycaemia causes glycation of tissues, which almost inevitably leads to acute disturbances in metabolism and long term end organ damage and severe health complications. In the United States there are nearly 16 million reported cases and an estimated 6 million undiagnosed. ${ }^{1}$ The worldwide prevalence of diabetes appears to be increasing, with estimates of $4.0 \%$ (135 million) in 1995 expected to rise to $5.4 \%$ (300 million) by the year 2025 . Thus diabetes and its complications are set to be an increasing burden on health care budgets and already account for $30 \%$ of the Medicare budget in the United States. ${ }^{2}$

Almost all diabetes falls into two categories: type 1, an absolute deficiency of insulin production, and type 2 , characterised by resistance to insulin and inadequate compensation. These were recently reclassified following a report by the expert committee on the diagnosis and classification of diabetes mellitus which has suggested removal of the terms "insulin dependent diabetes" and "non-insulin dependent diabetes", in use since 1979. Impaired glucose tolerance, gestational diabetes, and maturity onset diabetes of the young are among other conditions reclassified. ${ }^{3}$

\section{Normal blood glucose control}

AT REST

Blood glucose concentrations must be maintained within narrow limits. This is essential to prevent the acute and chronic complications seen in diabetes mellitus ${ }^{4}$ and is achieved through a balance between the processes that add and remove glucose from the normal circulation. In the fasting state, glucose is produced by the liver and closely balances the uptake and losses into body tissues, responding closely to the circulating plasma glucose concentrations. In the postprandial state glucose is absorbed through the alimentary system, causing a rise in blood glucose concentrations. Insulin is released which reduces hepatic glucose production and increases the 


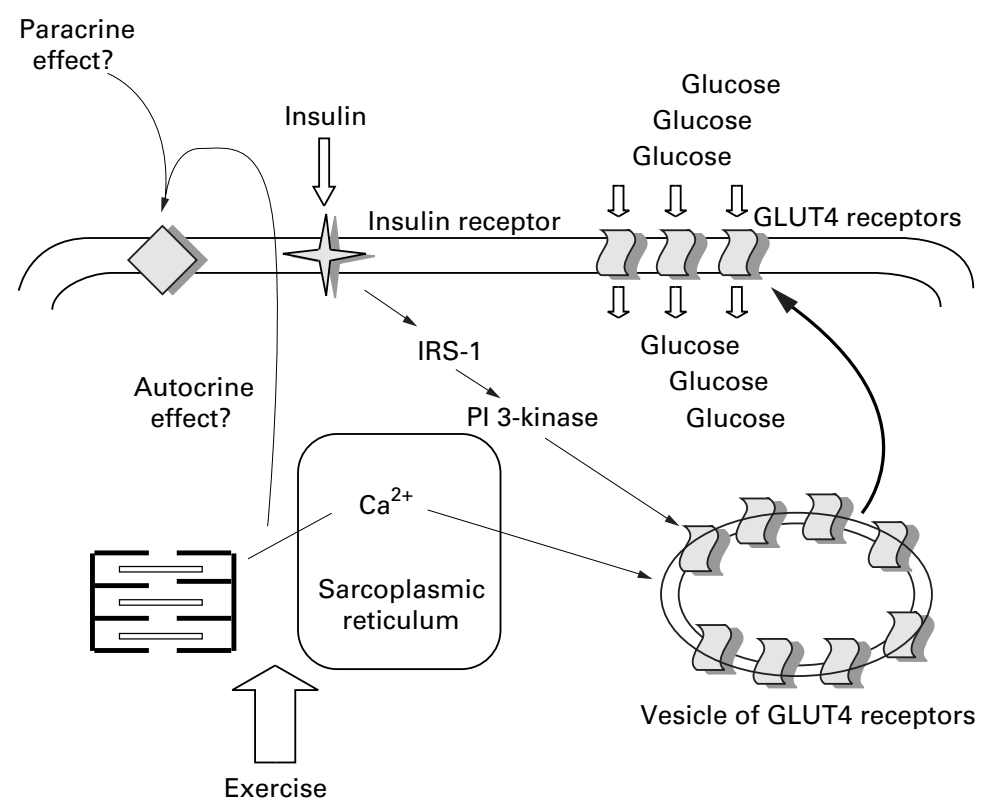

Figure 1 Glucose uptake in skeletal muscle. Insulin and exercise independently facilitate glucose transport across the mitochondrial membrane through promotion of GLUT4 transporters from the vesicles. The action is also cumulative producing enhanced glucose uptake/sensitivity during and after exercise. IRS-1, insulin receptor substrate 1; PI 3-kinase, phosphatidylinositol 3-kinase. Modified from Goodyear. ${ }^{147}$

disposal of glucose in peripheral tissue, thus reducing blood glucose. Some $90 \%$ of this clearance occurs through increased uptake in skeletal muscle where glucose is transported into muscle by facilitated diffusion. This occurs through the translocation of a family of transporter proteins to the membrane surface, almost all of which are the GLUT4 transporter (fig 1). A limited number of GLUT5 transporters are also present which allow relatively slow fructose transport.

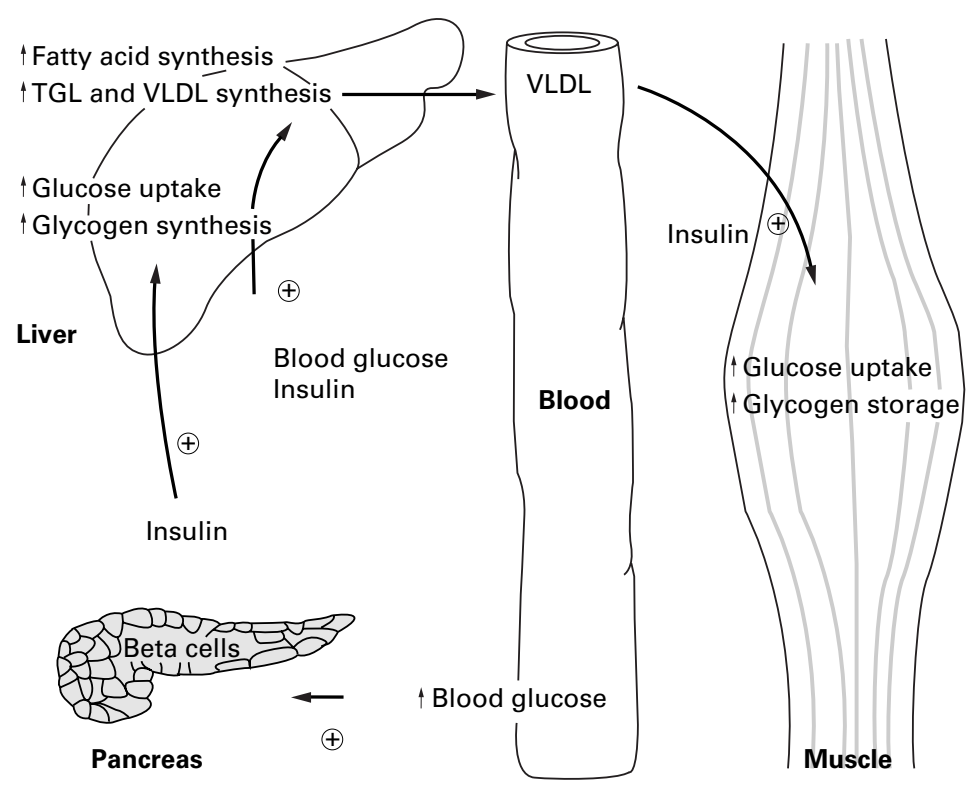

Figure 2 Actions of insulin. Insulin secretion from $\beta$-cells in the pancreas reduces hepatic glucose production while increasing glucose uptake in skeletal muscle. Lipid and glucose storage (as liver and muscle glycogen) is enhanced while lipolysis and ketone formation are suppressed. In type 1 and 2 diabetes the secretion and actions are reduced respectively. VLDL, very low density lipoprotein; TGL, triacylglycerol. Modified from Brooks et al. ${ }^{148}$
DURING EXERCISE

During exercise the large changes in energy utilisation require fine adjustments of glucose and non-esterified fatty acid concentrations within the blood. During the first 5-10 minutes of moderate intensity exercise, glycogen provides the major fuel source for skeletal muscle, but as exercise duration is prolonged, the contribution of plasma (blood borne) glucose and non-esterified fatty acid predominates. To match this increased demand, a complex hormonal and autonomic response allows an increase in hepatic glucose production and tissue uptake while increasing mobilisation of non-esterified fatty acid from adipose tissue deposits. This is produced both by a fall in circulating insulin concentrations and a wide variety of "counter-regulatory" hormones, increased secretion of which counters the hypoglycaemic action of insulin (fig 2). Elevations in the blood concentrations of these hormones, which include adrenaline, glucagon, cortisol, and growth hormone, promote both increased glucose production and mobilisation of nonesterified fatty acids from adipose storage sites. In addition, production of new glucose in the liver (gluconeogenesis) from substrates such as lactate is enhanced. Direct sympathetic stimulation of the pancreas and liver after muscle contraction may also bypass initial hormonal control, and additional fuel supplies are provided by ketone formation and mobilisation of lactate from inactive muscle glycogen.

Glucose transport into muscle is again provided by the transporter protein GLUT4, but the protein is recruited to the membrane surface in large quantities in contracting muscle, independently of insulin (fig 1). Together these changes maintain the increased fuel supply for exercising muscle and prevent hypoglycaemia from excessive utilisation.

\section{AFTER EXERCISE}

At the end of exercise the body in essence enters a fasted state in which glycogen stores in muscle and liver are low and hepatic glucose production is accelerated. The counterregulatory hormone levels may remain elevated for some considerable time and there is a concomitant hyperglycaemic and hyperinsulinaemic response. Glycogen resynthesis in the muscle occurs at first largely as a result of increased GLUT4 transport and insulin sensitivity and without the need for insulin. At a variable time point later, as homoeostasis is reached and glycogen, glucose, and hormone levels return to normal, insulin may be required to produce additional glucose uptake and glycogen resynthesis in muscle and liver. In the insulin deficient or resistant state, storage of glucose may therefore be impaired within muscle because of incomplete transport and decreased glycogen synthase activity.

\section{Type 1 diabetes}

In type 1 diabetes there is autoimmune destruction of the pancreas leading to a failure to secrete insulin. Although trials are underway to explore the prevention of this process, it is at present a relentless and chronic disorder. It 
represents the most common endocrinological disease of childhood affecting as many as 1 in 500 children under 18, and the incidence would appear to be increasing. ${ }^{1}$ Exogenous insulin is essential in the treatment of this condition and represents the only available treatment for approximating normal physiology. Since the introduction of insulin in the 1920s, when treatment was aimed at preventing ketoacidosis, the process of insulin administration has become more elaborate with increasing varieties and techniques. The aims of treatment for a diabetic now include mimicry of normal insulin levels throughout the day, achieving tight control, and prevention of microvascular and macrovascular complications.

BLOOD GLUCOSE CONTROL

Ambient insulin concentrations are vital in normal glucose homoeostasis both during exercise and in recovery. In type 1 diabetes the normal mechanism is lost and must be approximated using exogenous insulin, with consequent problems of excessive or insufficient insulin administration.

Excess insulin prevents normal hepatic glucose production and mobilisation of nonesterified fatty acids. In addition, whole body glucose disposal increases through facilitated muscle glucose uptake with the subsequent risk of exercise induced hypoglycaemia, ${ }^{56}$ exacerbated in turn if inappropriately injected into exercising muscle. ${ }^{7}$ The uptake of glucose into skeletal muscle can occur independently of insulin, but, because of the increase in insulin sensitivity after exercise and reduced liver and glycogen stores, glucose production cannot meet the excessive uptake, and thus hyperinsulinisation will also increase the risk of postexercise hypoglycaemia.

Despite the independent glucose uptake that occurs in skeletal muscle with exercise, a relative deficiency in the insulin dosage can result in hyperglycaemia, hyperlipidaemia, and possible ketosis. This can eventually lead to ketoacidosis and coma. Once exercise commences, this condition will deteriorate, with a further increase in the production of counterregulatory hormones, especially glucagon and adrenaline, producing elevated hepatic glucose production and impaired muscle glucose uptake and therefore further rises in blood glucose. Ketosis may also increase as lipolysis will be more pronounced. ${ }^{89}$ This exaggerated hyperglycaemia and ketosis occurs despite rising blood glucose concentrations and appears to be correlated with the initial ketotic state of the person. Berger et $a l^{10}$, in 1980, showed the importance of the pre-exercise state. Increases in pre-exercise values above the normal blood levels of non-esterified fatty acid $(1173 \mu \mathrm{mol} / \mathrm{l})$, glucose $(18 \mathrm{mmol} / \mathrm{l})$, ketone bodies (2.13 $\mathrm{mmol} / \mathrm{l}$ ), and branched chain amino acids $(0.74 \mathrm{mmol} / \mathrm{l})$ proved critical before three hours of cycling at $30-40 \% \mathrm{VO}_{2} \mathrm{MAX}$. Exaggerated glucagon and cortisol levels were observed which in turn promoted hyperlgycaemia and ketosis. Conversely exercise below these starting concentrations allowed an appropriate fall in blood glucose during the exercise period. ${ }^{10}$
However, these starting values are variable between subjects, and some trial and error may be required to establish them, which equally applies to intense exercise of shorter duration. Interestingly lactate production also appears to be higher in type 1 diabetes, which is possibly related to the increased production of counterregulatory hormones.

RISKS OF EXERCISE IN TYPE 1 DIABETES

The major risks to the exercising type 1 diabetic subject are potentially life threatening metabolic disturbances and the associated morbidity and mortality of microvascular and macrovascular complications. Despite the best precautions, hypoglycaemia can occur, and, although moderate exercise itself may not mask hypoglycaemic responses in patients with type 1 diabetes, during vigorous activity this feedback may be impaired, ${ }^{11}$ with additional orthostatic hypotension, impaired thermoregulaton, and neuropathy confusing the hypoglycaemic symptoms. ${ }^{12}$ These may be worse in the morning, ${ }^{13}$ and all patients with type 1 diabetes should carry rapidly absorbable high glycaemic carbohydrates/drinks, glucagon, or "Hypostop". The normal alcohol consumption that occurs after a game in many sports can also pose additional risks of exercise induced hypoglycaemia with a failure to recognise the warnings, occasionally seen as a problem in subaqua divers where "nitrogen narcosis" and exercise induced hypoglycaemia produce interchangeable symptoms.

Post-exercise hypoglycaemia and delayed onset hypoglycaemia can occur up to four and 24 hours after exercise respectively. The increased insulin sensitivity and depleted glycogen stores conspire to produce profound hypoglycaemia, most commonly nocturnal. ${ }^{14}$ This neuroglycopenia has been suggested to disturb sleep patterns, alter recovery, and therefore affect physical performance the following day and carries significant morbidity and mortality. Recent studies in this department have shown that one hour of nocturnal hypoglycaemia reduces the sense of wellbeing and increases subjective determinants of fatigue but produces no alterations in the hormonal, glucose, and lactate response to exercise. Interestingly, cerebral, cardiovascular, and physical performance also show no objective alterations. ${ }^{15}$ For the person concerned, nocturnal hypoglycaemia nevertheless remains an alarming risk, and an evening snack or reduced evening dose of insulin after activity may be warranted. Hyperglycaemia as discussed above produces both acute and long term consequences, increasing the risks of cardiovascular disease, sudden death, reduced exercise capacity, hypertension, retinopathy, nephropathy, and neuropathy, which can all significantly worsen with impaired control. These complications will be discussed below.

There are a large number of significant physical and psychological benefits of exercise which demand regular physical activity where possible. Unfortunately the evidence for improvements in glycaemic control in type 1 diabetes are not well established. Only a 
handful of studies, often relatively small, have provided mixed evidence for improvements in glycaemic control. Several have shown reduced insulin secretion and hypoglycaemia but little reduction in $\mathrm{HbA} 1 \mathrm{c},{ }^{16-18}$ although when activity was stratified according to participation, metabolic control was significantly better among diabetic subjects participating frequently (at least 11 of 13 sessions), regardless of the type of activity. ${ }^{19}$ More recently a study of 61 subjects with type 1 diabetes showed that modest changes in exercise and diet were sufficient to improve measures of glycaemic control and lipoprotein mediated risk of coronary heart disease..$^{20}$ In addition, some evidence suggests that the timing of exercise is an important factor, with regular postprandial exercise improving long term blood glucose control. ${ }^{21}$

\section{AIMS OF TREATMENT}

The diabetes control and complications trial and more recently the UK prevention of diabetes study have both shown conclusively that tight control helps to prevent the development of macrovascular and microvascular complications. Thus the aims of treatment should be to keep blood glucose concentration between 4 and $7.2 \mathrm{mmol} / 1$ and to prevent large and significant swings either below $3.0 \mathrm{mmol} / 1$, leading to symptomatic hypoglycaemia, or above $8-10 \mathrm{mmol} / \mathrm{l}$, increasing the immediate and long term complications. However, with extremely tight control, there is a potential for an increased risk of hypoglycaemia during exercise. Thus personalised insulin regimens and nutritional strategies in advance of physical activity need to be adapted.

INSULIN REGIMENS

Insulin regimens should be tailored to each patient. One to one education and establishing self empowerment have been shown to significantly improve glycaemic control but, unfortunately, a degree of trial and error is necessary for all patients with type 1 diabetes taking up any new activities.

Insulin regimens for most patients range between 0.5 and $1.0 \mathrm{U} / \mathrm{kg} /$ day. This dose may be reduced in lean subjects, athletes, and during the honeymoon period, which can be prolonged in diabetic athletes. In these groups insulin doses are between 0.2 and $0.6 \mathrm{U} / \mathrm{kg} /$ day. Traditionally, regimens sought to provide a basal insulin presence by injection of intermediate or long acting insulin once or twice a day,

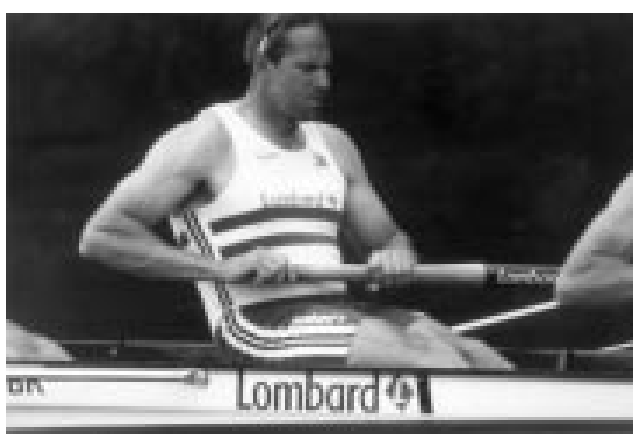

Figure 3 Steven Redgrave. administered in the morning and evening and amounting to $50 \%$ of the daily insulin dose. Additional fast acting regular insulins were then introduced and given with breakfast, lunch, and sometimes dinner. Unfortunately the presence of longer acting insulins produces a significant risk of hypoglycaemia during the midmorning or afternoon and at night, which is exaggerated in the exercising diabetic.

To improve tight control, intensive insulin regimens with regular self monitoring of glucose are now used widely by exercising patients with type 1 diabetes. These intensive multiple component regimens include regular mealtime injections of short acting insulin analogues (onset of action 15-30 minutes), such as Lispro, or regular insulins (onset 30-60 minutes), with a lower dose of intermediate acting insulin once or twice a day to provide a low basal insulin presence. In the exercising diabetic this may be best served by a low dose intermediate acting insulin injection in the evening only, to prevent hypoglycaemia during the day, although this may promote increased blood glucose levels during the following day. Some studies report common exercise induced hypoglycaemia, ${ }^{62}$ but an intensive education programme in 700 subjects $^{23}$ showed that large reductions in exercise induced hypoglycaemia can be achieved by careful planning.

\section{Moderate exercise}

Any physical activity including household chores may reduce daily insulin requirement. If it is only 20-30 minutes duration and less than $70 \% \mathrm{Vo}_{2} \mathrm{MAX}$, minimal adjustments may be need to be made. If early morning physical activity is to be performed, the basal insulin provided by an evening injection of intermediate to long acting insulin may need to be reduced by $20-50 \%$ with checking of the morning blood glucose. Increases of more than 7-8 $\mathrm{mmol} / \mathrm{l}$ may compromise long term control, although levels below 10-12 mmol/1 will allow safe exercise. Conversely, levels below $6 \mathrm{mmol} / 1$ may increase the risk of hypoglycaemia even if the exercise intensity is likely to be moderate (50-70\%). The morning regular acting insulin dose will also need to be reduced by $30-50 \%$ before breakfast or even omitted if exercise is taken before food. Insulin should otherwise be taken 30-60 minutes before the meal as usual. Depending on the intensity and duration of the initial activity and the likelihood of further activity, a similar reduction of $30-50 \%$ may need to be made with each subsequent meal. After exercise, hyperglycaemia will occur. However, insulin doses should still be reduced by $25-50 \%$.

If exercise is unexpected, then adjustment of insulin dosage will be impossible. Instead supplementing with 20-30 g carbohydrate-that is, a carton of orange juice or an energy bar-at the onset of exercise and every 30 minutes thereafter may prevent hypoglycaemia.

\section{Elite athletes and intense activity}

The elite athlete provides both a unique challenge and a unique resource. As a possible role model they provide a focus for diabetics 
Table 1 Metabolic control in type 1 diabetes

\begin{tabular}{|c|c|}
\hline Monitor & Action \\
\hline Establish good control before exercise & If unstable avoid exercise until control established \\
\hline Check nature of exercise, ambient conditions, changes in weight, hydration status & Adjust for cold/ heat/ winds/ weight loss/ intense game/ activity \\
\hline Blood glucose $>14 \mathrm{mmol} / 1(250 \mathrm{mg} / \mathrm{dl})$ ketosis $\left(1-2^{++}\right)$urinalysis & Avoid exercise \\
\hline Blood glucose $>17 \mathrm{mmol} / 1(300 \mathrm{mg} / \mathrm{dl})$ & Avoid exercise \\
\hline Blood glucose $<5.5-6.0 \mathrm{mmol} / 1(100 \mathrm{mg} / \mathrm{dl})$ & $\begin{array}{l}\text { Ingest extra carbohydrate and avoid vigorous or prolonged exercise unless } \\
\text { established protocol }\end{array}$ \\
\hline Monitor glucose before and after exercise & $\begin{array}{l}\text { Establish routine and response to exercise, identify changes required before } \\
\text { activity, identify symptoms of hypoglycaemia }\end{array}$ \\
\hline Establish timing and quantity of food & $\begin{array}{l}\text { Allow for delayed gastric emptying for glucose absorption and discomfort. } \\
\text { Provide readily available and absorbable carbohydrate }\end{array}$ \\
\hline Adjust insulin doses according to intensity of exercise & $\begin{array}{l}\text { For moderate intensity exercise allow } 50 \% \text { reduction in insulin dosages. For } \\
\text { high/prolonged intensity reduce dose by } 70-90 \%\end{array}$ \\
\hline
\end{tabular}

throughout their home country. In the United Kingdom, Gary Mabbut and Steven Redgrave (fig 3) are household names and have contributed to normalising attitudes towards exercise and diabetes. Many doctors find it remarkable that people with type 1 diabetes can compete at the highest level. Despite this attention, however, most athletes even now find most information to be vague, limited, and often of little relevance, and some have even put these thoughts in print in the hope of helping others. ${ }^{1324}$

It is extremely important for an elite athlete to establish habitual training programmes that mimic competition. If the exercise intensity is sufficiently high or competitive, insulin may even be omitted at the beginning of competition, although the recommendations need careful individual attention. A reduction of $70-90 \%$ is more likely to be appropriate in such situations, which applies equally to extremely intense prolonged exercise, such as is encountered in marathons and triathlons, ${ }^{25}$ and vigorous team sports with interrupted activity such as rugby, football, and hockey. Additional carbohydrates may need to be taken on board and blood sugar checked at changeovers/half time, if necessary. A reduction of $50-70 \%$ in insulin administered the night before may also be necessary to prevent long acting insulins from increasing hypoglycaemia during early morning exercise and may also be required for 24-36 hours after intense exercise.

Both elite and recreational diabetic athletes can also learn to identify hyperglycaemia $(>14$ $\mathrm{mmol} / \mathrm{l}$ glucose) which may be manifested as poor concentration, dehydration, or even under confidence. In the period after exercise, hyperglycaemia can arise from continued glucose production and reduced disposal, and an increase in insulin dose may be necessary. Care should be taken with this dose, which will need to be relatively low, as the risk of post-exercise hypoglycaemia is increased because of enhanced insulin sensitivity and low glycogen stores. Consideration must also be given to any additional medication that may promote hypoglycaemia or hyperglycaemia, and one must also be alert to the possible use of anabolic agents such anabolic steroids and stimulants which may all worsen hyperglycaemia.

With regular attention and simple strategies (table 1), it is possible to achieve both adequate control and high intensity exercise. During periods of inactivity such as holidays or recov- ery from injury increased insulin requirements are to be expected.

SITE OF INJECTIONS AND GLUCOSE MONITORING Standard advice should include establishing a routine site and technique and avoiding injecting into the exercising leg ${ }^{26}$, although hypoglycaemia cannot be averted by simply altering the site. Care needs to be taken to avoid intramuscular injections, ${ }^{7}$ and in hot or warm ambient conditions absorption may also be increased. The most common site used by athletes appears to be the abdomen as this allows ease of access at meal times and is least likely to affect performance.

Ideally, monitoring should be undertaken each morning, before and after exercise and before and after meals. Computer programs have also been suggested, ${ }^{27}$ and athletes involved in potentially dangerous activities such as scuba diving should check blood glucose at 90, 30 and five minutes before exercise. This shows the direction of blood glucose changes, which should be stable. Blood glucose monitoring kits are now small and portable and should be kept within easy access at all times.

INSULIN PUMPS

These have come into vogue and "pumpies" are increasingly using continuous subcutaneous insulin infusion pumps for treatment during elite sports participation. They have been in use for 20 years, ${ }^{28}$ and increasing numbers of elite athletes are using the pumps to secure intensive insulin regimens, tight control, and increased flexibility. Studies on continuous subcutaneous insulin infusion have shown that reducing the action of the pump by $50 \%$ before exercise, similar to multiple component regimens, prevents hypoglycaemia. ${ }^{29-31}$

\section{LISPRO}

Lispro is a rapid acting insulin analogue which has recently been developed, particularly for injection immediately before a meal. Its rapid absorption and short duration of action provide several advantages, and, although reports on Lispro and exercise are limited, the use of a shorter acting analogue will probably allow a greater degree of flexibility and the ability to accommodate short term planning or unexpected exercise. ${ }^{32}$

PERFORMANCE

Traditionally it has been felt that diabetics, especially over 35 years of age, cannot succeed at the highest level of athletic endeavour. 
However, there are now a sufficient number of professional athletes, Olympic gold medallists, and world champions with type 1 diabetes to make us question the limits of the disease process. Relatively few studies have investigated performance parameters in the elite type 1 diabetic population. Certainly patients with diabetic neuropathy may have an increased risk of falling and injuries secondary to instability and reduced muscle strength. People with type 1 diabetes have a greater proportion of type 2 muscle fibres under conditions of hyperinsulinaemia with a consequent reduction in absolute strength; however, they adapt normally to strength and endurance with appropriate increases in muscle fibre type. Other studies show reduced left ventricular function and maximal oxygen consumption in association with type 1 diabetes, but all show improvement with training. Even impaired secretion of endogenous opioids in type 1 diabetes has been suggested to alter performance.

\section{NUTRITION}

The use of an intensive insulin regimen requires careful attention to nutrition. With delayed gastric emptying often present, adjustments in dietary regimens to suit personal preferences, such as liquid supplements, may be required. Meals may also need to be taken between three and five hours before exercise. "Counting the carbohydrate" content of meals has become increasingly popular as a means of adjusting insulin doses and dietary calories. An individual ratio of 1 unit of insulin per $10 \mathrm{~g}$ carbohydrate is widely advocated, with adjustments made for the intensity or duration of exercise. Many athletes use programmes such as the "ex-carbs" and the "450 program" which have been formularised and advocated within athletic circles but have not been studied. A balanced diet needs to take into account energy requirements and should provide $60 \%$ of total energy expenditure as carbohydrates $(5-10 \mathrm{~g} / \mathrm{kg} /$ day depending on exercise intensity and duration) before, during, and after exercise. This should be accompanied by additional fluids and protein $(0.6-1.2 \mathrm{~g} / \mathrm{kg} /$ day $)$ and a reduction in fat, less than 30-40 g a day.

\section{Type 2 diabetes}

Type 2 diabetes (formerly known as noninsulin dependent diabetes mellitus) occurs almost exclusively in the adult population and its main feature is insulin resistance, manifested as hyperinsulinaemia and hyperglycaemia. It is strongly correlated with obesity, physical inactivity, and family history and accounts for $90 \%$ of all diabetes. Typically as many as $80 \%$ are overweight and many are elderly. Not surprisingly the incidence of the disease is increasing in western societies.

PHYSIOLOGY OF EXERCISE AND TRAINING IN IMPAIRED GLUCOSE TOLERANCE AND TYPE 2 DIABETES

Many of the extreme changes in metabolism seen in type 1 diabetes are blunted. Instead hyperinsulinism and hyperglycaemia are present concurrently because of the preserva- tion of pancreatic $\beta$-cell function and hepatic and skeletal muscle insulin resistance, with hypoglycaemia therefore relatively uncommon. The initial presentation of type 2 diabetes is as insulin resistance, an impaired response to endogenous insulin, and therefore impaired glucose tolerance. As with type 1 diabetes, exercise produces increased glucose uptake in skeletal muscle. Unlike in type 1 diabetes, however, those with type 2 diabetes are able to produce significant decreases in ambient blood glucose and insulin concentrations without increasing the risk of hypoglycaemia. This is due in part to reduced hepatic glucose production but mainly to increased muscle glucose uptake through increased delivery, oxidation, and storage of carbohydrates. In type 2 diabetes, this increased uptake appears to bypass the normal regulation at rest and promotes increased glucose uptake for up to several hours with a concomitant fall in glycaemia. ${ }^{33} \mathrm{~A}$ single exercise bout has been shown to increase insulin sensitivity in liver and muscle for up to 16 hours $^{34}$ while prolonged exercise produces a fall in hyperglycaemia and hyperinsulinaemia. ${ }^{35}$

Initially athletes were noticed to have reduced plasma glucose and insulin concentrations in response to oral glucose loading, ${ }^{40}$ with the suggestion that exercise improved insulin sensitivity. ${ }^{41}$ The increase in insulin sensitivity with exercise has since been well established, ${ }^{42-44}$ and controlled studies of exercise intervention/training have resulted in improved insulin sensitivity, ${ }^{45}$ increased carbohydrate oxidation, and reductions in body mass. ${ }^{46}$ Hughes et $a l^{47}$ showed an improvement in insulin sensitivity with training at $50-70 \%$ $\mathrm{VO}_{2} \mathrm{MAX}$, and many studies have reported immediate changes in total glucose disposal $^{34} 4849$ and skeletal muscle uptake. ${ }^{45} 5051$ In subjects who trained vigorously, improvements in glucose disposal were double for up to 10 days. $^{52}$ These beneficial effects of training unfortunately appear to be transient, declining after seven days ${ }^{53}$ and 10 days, ${ }^{47} 5455$ and are in part derived from increased GLUT4 transporter recruitment, which has also been shown to be higher in athletes ${ }^{56}$ and after training. ${ }^{47} 57$ In addition, exercise and training promote increased blood flow, insulin receptor, and oxidative and non-oxidative enzyme concentrations in muscle. Although aerobic training also promotes the transition to a greater percentage of type 1 and 2 a muscle fibres, the importance of this is not fully understood. Instead the preservation of the lean body tissues, in particular muscle mass, and the reductions in fat mass appear to be significant contributors to improved insulin sensitivity. ${ }^{51}$ Although the risks of hypoglycaemia in type 2 diabetes appear small, conflicting advice on concomitant exercise and treatment with sulphonylureas is still given. Caution when undertaking vigorous exercise should therefore be encouraged, as some reports of hypoglycaemia exist. ${ }^{36-38}$ Metformin has also been linked with type $B$ lactic acidosis and its use is probably inappropriate during intense exercise. ${ }^{39}$ 
However, do these immediate changes in the actions of insulin produce long term adaptive benefits? ${ }^{58}$

EPIDEMIOLOGY OF PHYSICAL ACTIVITY AND

IMPROVED GLYCAEMIC CONTROL

Early studies indicated that prolonged bed rest was associated with impaired glucose tolerance. ${ }^{49} 59$ Epidemiological evidence has strongly pointed to a number of correlates of physical inactivity promoting type 2 diabetes, ${ }^{60}$ including lack of vigorous exercise, reduced energy expenditure, aging, aerobic capacity, heart rate changes, and time spent exercising. ${ }^{61}{ }^{62}$ Importantly these studies also suggest that physical activity can reduce the risk of developing type 2 diabetes. In those individuals with impaired glucose tolerance ${ }^{6163-66}$ the relative risk over five years was approximately $0.70(\mathrm{p}=0.0006)$ for participants who exercised vigorously in comparison with sedentary subjects. ${ }^{60-626768} \mathrm{In}$ high risk groups such as those with a family history of diabetes mellitus or increased body mass index there is a beneficial outcome from regular physical activity, also shown in the large cohort studies of college alumni ${ }^{61}$ and nurses. These studies show a $6 \%$ reduction in the prevalence of type 2 diabetes with each 2.09 MJ of estimated recreational activity. ${ }^{65}$ The recent insulin resistance atherosclerosis study showed improved insulin sensitivity in both non-vigorous ( $<6$ metabolic equivalent levels; METS) and vigorous (>6 METS) exercise. ${ }^{69-71}$

EXERCISE TRIALS TO PREVENT DIABETES

Some $30-40 \%$ of people with impaired glucose tolerance progress to type 2 diabetes at a rate of $1-1.5 \%$ per year, and several large studies have explored the relation between exercise and the prevention of the onset of diabetes. The diabetes prevention study in Finland showed that simple lifestyle changes including diet and moderate exercise decreased two hour glucose $(0.9 \mathrm{mmol})$ and insulin $(22.5 \mathrm{U} / \mathrm{ml})$ after an oral glucose tolerance test. ${ }^{72}$ In China, the Da Quing impaired glucose tolerance study followed 577 subjects with impaired glucose tolerance for six years; a $31 \%, 46 \%$, and $42 \%$ reduction in the risk of developing diabetes was associated with diet, exercise, and diet plus exercise respectively. ${ }^{73}$ The Oslo diet and exercise study randomised 219 men and women to a one year participation in supervised exercise (aerobic exercise three times a week) and dietary changes (fish and reduced fat) and showed significant benefits in insulin sensitivity especially using the combined approach. ${ }^{74}$

The Malmo prevention study, first reported several years ago, ${ }^{64}{ }^{66}$ has shown, after 12 years follow up, reduced mortality in patients with impaired glucose tolerance (increased risk of both developing type 2 diabetes and premature death from ischaemic heart disease) and a reduction in type 2 diabetes by $50 \% .^{75}$ The diabetic prevention project in Washington DC is at present examining impaired glucose tolerance; 855 patients have been randomised to taking troglitazone or metformin or lifestyle changes.
The potential to improve health in a population in which up to two out of every three adults are not regularly active at all ${ }^{25}{ }^{76}$ is staggering. However, considerable work is needed in many areas such as the benefits of educating children and the young ${ }^{40} 527$, the intensity of the exercise that is most beneficial ${ }^{78}$, and the most appropriate timing of any interventions, given the occult nature of diabetes and risk factors. ${ }^{79}$

\section{Exercise benefits}

The prescription of exercise for diabetic control should be considered for a variety of associated and independent health benefits. The full scope of these benefits can be seen in a number of reviews and include weight loss, weight loss maintenance, lipid profiles, blood pressure, psychological profile, and the constellation of symptoms that make up the metabolic/Reaven syndrome $\mathrm{X}^{80-82}$ It would appear that exercise and diet provide the first and possibly most effective interventions in improving cardiovascular risk, ${ }^{83-86}$ with exercise intervention studies now showing reduced death rates $(6.5 v 14.0 ; \mathrm{p}=0.009)$ in those with impaired glucose tolerance. ${ }^{75}$

It has become evident that possibly the most important role for exercise will be in weight loss and weight loss maintenance. A loss of $4.5 \mathrm{~kg}$ or more appears to be critical in preventing the development of covert diabetes and reducing blood pressure, ${ }^{87}$ and evidence for the importance of exercise in increasing weight loss and helping maintain weight loss with subsequent improvements in type 2 diabetes is now overwhelming.

\section{Exercise prescription}

Once a patient has been screened and the risk factors and exercise capacity determined, regular exercise may then be considered. The typical patient with type 2 diabetes is sedentary, overweight, and middle aged or older ${ }^{88}$ In this group of patients, exercise may well be beneficial but needs to be carefully implemented. Guidelines issued jointly by the American Diabetes Association (ADA) and the American College of Sports Medicine (ACSM) suggest a gentle warm up period of 5-10 minutes, a period of stretching, and then an active cool down period of 5-10 minutes to allow gradual adjustment of heart rate and blood pressure. ${ }^{89}$ The intensity, duration, and frequency of exercise necessary for good health has been adjusted from the $60-80 \%$ of maximal oxygen consumption outlined in the ACSM guidelines in 1976. Instead the target of an adult should be to achieve 30 minutes of continuous moderate activity, equivalent to brisk walking on five or six days a week, ${ }^{60}$ with the flexibility of shorter bouts of more intense activity increasingly being considered important. Vigorous activity is widely implicated in health benefits and can be safely undertaken in diabetics provided that cardiovascular and hypertensive problems are taken into consideration. As no studies have accurately defined the most suitable exercise programme for diabetics, it is inappropriate to be too prescrip- 
Table 2 Evaluation of subject before exercise

Evaluation

History, age, duration of disease, family history

Examination

Cardiovascular

Blood pressure

Retinal examination (table 4)

Neuropathy (tables 5 and 6 )

Vascular

Foot

Exercise stress test (table 3)

Blood $\mathrm{HbA1c}$, lipid profile, renal function

Urinalysis, glycosuria, microalbumin, protein, ketones

tive and instead we should concentrate on adherence and compliance. ${ }^{90}$ When ACSM guidelines are used, there is a drop out rate of $40-70 \%$ after $12-18$ months despite an active intervention programme.${ }^{91}$ However, the recent guidelines have gained wider acceptance ${ }^{92}$ and much greater success has been reported in the Malmo intervention studies ${ }^{93}$ for relatively informal exercise programmes ${ }^{94}$ with mixed high and low intensity exercise $e^{95}$, although exercise below $30 \% \mathrm{VO}_{2} \mathrm{MAX}$ may have little benefit. $^{96}$ In general, exercise programmes appear to be safe, with a very low incidence of hypoglycaemia, a $12 \%$ incidence of musculoskeletal injuries, and $29 \%$ increase in proteinuria of unknown significance. In part because of autonomic neuropathy, heart rate may be an unreliable indicator of relative intensity of exercise and therefore the rating of perceived exertion scales may be a more useful predictor of $50-70 \% \mathrm{VO}_{2} \mathrm{MAX}^{97}$

Exercise prescription must also take into account patients' readiness to exercise, attitudes, and belief systems, while positively encouraging decisions to exercise. Support can be provided through a team of doctors, nurses, physiotherapists, lifestyle counsellors, and exercise consultants and even through health policy decision-making at government and local level. ${ }^{98} 99$

\section{Screening}

For safe participation in activity, patients of any age should have regular medical examinations to predict and prevent major complications. Exercise intensity and activities can then be planned accordingly. A routine examination should include the points outlined in table 2 and further specific tests initiated as appropriate.

\section{NEPHROPATHY}

Nephropathy occurs in $20-40 \%$ of patients with type 1 and type 2 diabetes, and, when combined with hypertension, with which it is strongly correlated, it accounts for one fifth of all end stage renal disease. Nephropathy is classified according to urinary albumin excretion rates: $<20 \mu \mathrm{g} / \mathrm{min}$, normoalbuminuria; $20-200 \mu \mathrm{g} / \mathrm{min}$, incipient nephropathy; >200 $\mu \mathrm{g} / \mathrm{min}$, overt nephropathy. ${ }^{100}$ Although exercise increases albumin excretion, there is no evidence that this hastens the progression of nephropathy, even though exercise induced albumin excretion was once used as a diagnosis of covert nephropathy. Instead improved glycaemic control and maintenance of normal blood pressure can help slow overall progression of macrovascular disease and mortality, ${ }^{4}{ }^{101}$ and, as exercise both raises blood pressure acutely and helps to reduce blood pressure chronically, the benefits are not clear cut. One small study showed no detriment to renal function after exercise, ${ }^{102}$ but at present no guidelines exist on either the benefits or risks of exercise in the presence of nephropathy. The ADA/ACSM has suggested that participation may need to be limited, but has not defined this. However, it would appear sensible to consider the strong association of renal disease with associated risk factors of hypertension and microvascular and macrovascular complications, and therefore restrict those with overt nephropathy to moderate intensity activity. In addition, the presence of anaemia or uraemic myopathy and taking medications such as antihypertensive drugs (up to $30 \%$ of diabetics require triple antihypertensive treatment) may all reduce exercise capacity. In dialysis patients, exercise capacity is reduced but this can be increased by exercise training, dietary changes, erythropoietin administration, and ultimately renal transplant. ${ }^{103}$

CARDIOVASCULAR DISEASE

Atherosclerosis, hypertension, ${ }^{104}$ and cardiomyopathy ${ }^{105}$ are more common in diabetes with the relative risk doubled for myocardial events and sudden death, especially in the young. Ischaemic heart disease is present in $50 \%$ of patients with type 2 diabetes at the time of initial diagnosis, ${ }^{106}$ with early signs of cardiovascular disease and reduced performance capacity ${ }^{107}$ predicting the likelihood of future cardiac events and ischaemic heart disease. ${ }^{108}$ These are increased 2- and 4-fold in male and female patients with type 2 diabetes respectively ${ }^{109}$ and 3-10-fold in those with type 1 diabetes. ${ }^{110-115}$ Complications include reduced left ventricular function, higher resting heart rates, reduced cardiac reserve, reduced cardiac return, orthostatic hypotension, and coronary artery stenosis. ${ }^{116-120}$ In addition, hypoglycaemia may promote prolongation of PR and QT intervals, promoting arrhythmias during exercise.

Hypertension is also more prevalent in type 1 and type 2 diabetes than in the background population, especially in younger patients. ${ }^{65101121-124}$ Appropriate control is necessary, as systolic blood pressure rises may be higher during exercise ${ }^{123-125}$; however, blood pressure can be reduced by $5-10 \mathrm{~mm} \mathrm{Hg}$ after 10 weeks training and this may be sufficient with concomitant weight reduction to establish normotension. ${ }^{126}$ Treatment needs to consider potential reductions in performance and exercise induced systolic pressure, and ultimately participation will depend on an informed decision, with exercise above $70 \% \mathrm{VO}_{2} \mathrm{MAX}$ and use of isometric contractions restricted. Protocols for resistance training can be found in the ACSM guidelines, ${ }^{127}$ and appropriate references include the guidelines for prevention, detection, evaluation, and treatment of hypertension by the Joint National Committee VI. ${ }^{87}$ In addition, recently the UK prevention of 
Table 3 Modified ACSM/ADA screening protocol

Cardiovascular risk factors demanding exercise stress testing ${ }^{89}$

Vigorous/elite activity

Type $2>10$ years

Type $1>15$ years

$>35$ years of age

Any coronary artery disease risk factors

Any macrovascular disease

Any microvascular disease

Peripheral vascular disease

diabetes study has shown equal benefit from $\beta$-blockers and angiotensin converting enzyme inhibitors for prevention of macrovascular complications. ${ }^{101122}$

Table 3, adapted from ACSM/ADA, recommends pre-exercise screening, with stress testing for the cardiovascular risk stratification which should be considered as a minimum. Abnormal results may then demand appropriate management and planned intensity of exercise prescription.

RETINOPATHY

The presence of retinopathy should always be suspected in any diabetic patient and should form part of any routine assessment before participation in exercise. Some $98 \%$ of cases of type 1 diabetes and $78 \%$ of cases of type 2 diabetes will progress, resulting in detectable changes 15 years from diagnosis ${ }^{128}$, correlating with duration of disease, poor control, hypertension, hyperlipidaemia, fluid overload, and renal disease. Diabetic retinopathy can be simplified as non-proliferative or proliferative, with the natural progression of the latter to blindness in approximately $3-5 \%$ of cases. Patients with proliferative diabetic retinopathy have abnormal haemodynamic responses of the cerebral and ophthalmic circulation both at rest and with exercise. ${ }^{129} \mathrm{~A}$ reduced exercise capacity is seen with proliferative ${ }^{117}$ and non-proliferative ${ }^{130}$ diabetic retinopathy in type 1 diabetes. Vigorous physical activity, especially isometric contractions, produces significant increases in blood pressure and can accelerate proliferative diabetic retinopathy with significant risk of retinal and vitreal haemorrhage and detachment. Therefore caution should be considered when proliferative diabetic retinopathy is present, and guidelines have been provided by the ADA/ACSM that should form part of any recommendations for valsalva-like manoeuvres (table 4 ).

AUTONOMIC NEUROPATHY

Diabetic neuropathy presents in an occult manner in $17-40 \%$ of diabetics, with subclinical abnormalities in type 1 diabetes frequently
Table 5 Clinical signs of autonomic neuropathy

Signs

Cardiovascular

Hypotension during and after exercise (esp. vigorous activity)

Hypertension during exercise

Orthostatic hypotension (may be worse in the morning)

Cardiac denervation syndrome

reduced maximal heart rate

raised resting heart rate

Silent ischaemia

Impaired thermoregulation in hot and cold climate

Altered sweating

Altered cutaneous blood flow

Impaired proprioception (increased injury potential)

Impaired respiratory reflexes

Delayed gastric emptying

Diarrhoea

Impaired perception of hypoglycaemia

Pupillary

Table 6 Specific tests for autonomic neuropathy

Tests

\section{Sensory}

Vibration, temperature

Biothesiometer

Reflexes

Proprioception

Respiratory rate

Cardiac

Resting heart rate $>100$ beats $/$ min raised

$R-R$ variation changes with respiration

Valsalva manoeuvre

Orthostatic response systolic

Diastolic response to exercise

QT interval corrected

found within a year of diagnosis. ${ }^{131}{ }^{132}$ It can present with somatic or autonomic changes (table 5) with a variety of different neuropathies possible, including amyotrophy, mononeuropathy, and entrapment syndrome..$^{25} 131$ The symptoms and signs may be subtle, necessitating careful examination with the aid of special tests (table 6). The autonomic nervous system is involved in all involuntary regulations, essential for unimpaired exercise capacity, and neuropathy can produce a wide variety of effects (table 5). The most important of these include silent myocardial ischaemia, sudden death, hypertension and hypotension after exercise, delayed gastric emptying, and impaired sweating. ${ }^{130}{ }^{133-135}$ In the presence of peripheral neuropathy, $50 \%$ of patients are likely to have autonomic complications ${ }^{136} 137$

Cardiac autonomic neuropathy also produces impaired blood pressure control and can result in cardiac denervation syndrome whereby heart rate cannot be increased in response to exercise. ${ }^{138}$ Prolongation of the QT interval corrected for heart rate is more common than usual in diabetics, predisposing them to arrhythmias and sudden death, ${ }^{139} 140$ and cardiac autonomic neuropathy appears to

Table 4 Exercise guidelines in retinopathy

\begin{tabular}{llll}
\hline Level of diabetic retinopathy & Acceptable activities & Discouraged activities & $\begin{array}{l}\text { Ocular re-evaluation } \\
\text { (months) }\end{array}$ \\
\hline $\begin{array}{l}\text { None } \\
\text { Non-proliferative }\end{array}$ & $\star$ & $\star$ & 12 \\
$\begin{array}{l}\text { Mild } \\
\text { Moderate }\end{array}$ & $\star$ & $\star$ & $6-12$ \\
$\begin{array}{l}\text { Severe } \\
\text { Proliferative }\end{array}$ & $\star$ & Dramatic increase in BP e.g. weights, valsalva & $4-6$ \\
& Low impact, aerobic & $\begin{array}{l}\text { Substantial inc. BP e.g. boxing, rowing. High } \\
\text { impact, anaerobic, aerobic, racquet }\end{array}$ & $1-2$ \\
\hline
\end{tabular}

${ }^{\star}$ Dictated by medical status. Modified from ACSM/ADA guidelines. ${ }^{89}$ 
be associated with reduced cardiovascular function. ${ }^{121}$ Formal cardiovascular stress testing may be prudent before the initiation of an exercise programme in such patients. ${ }^{141}$ In addition, blunted adrenaline and noradrenaline responses may contribute to orthostatic impairment. ${ }^{142}$

\section{PERIPHERAL VASCULAR DISEASE AND FOOT}

ULCERS

The management of any exercising diabetic demands careful attention to the increased risk of foot ulceration and impaired vascular supply. Several reviews ${ }^{2} 143$ highlight the fact that neuropathy and peripheral vascular disease can predict unnoticed foot injury. Footwear that relieves forefoot plantar pressure by up to $50 \%$ has been shown to be effective in preventing the recurrence of foot ulcers when worn for more than $60 \%$ of the day, ${ }^{144}$ and it would appear that running shoes that protect the second and third metatarsal heads benefit patients significantly. ${ }^{145}$

\section{Guidelines and resources}

Even though ACSM and Sports Medicine Australia have determined that diabetes should be classified as a significant risk factor in any preparticipation physical examination, ${ }^{89} 146$ it seems surprising that there are so few published guidelines on physical activity and diabetes. Only the ACSM/ADA ${ }^{89}$ position statement with a recent outline from the International Sports Medicine Federation, not yet widely available in print, has attempted to address this.

In addition, there are relatively few definitive texts. The ADA provides significant resources, including the Health professional guide to diabetes and exercise and supports ${ }^{25}$ the International Diabetic Athletes Association. This provides information and a forum for diabetic athletes to exchange ideas and techniques and has chapters in many countries.

\section{Summary}

As the understanding of the physiology of exercise and the treatment options in diabetes mellitus improve, the ability to combine tight control and normal exercise in type 1 diabetes appears increasingly possible. Exercise has not been shown definitively to improve glycaemic control in type 1 diabetes, but, with education and appropriate screening, it allows substantial physical and psychological rewards to be realised. In type 2 diabetes evidence for the role of exercise in the management of the disease is increasingly powerful and exercise may well be an important component of strategies for prevention and treatment. Further studies are required to determine what the exact nature of this exercise should be, but developments in the field of diabetes, such as the increasing evidence of genetic and cultural differences in insulin sensitivity, may change many aspects of our care. A more complete understanding of exercise and the health benefits that it can bring can only produce further improvements in the prevention, management, and treatment of diabetes.
I am grateful to Drs Peter Mansell, Siun Campbell, and Julie Lambourne for their support in the production of this review.

1 Landry GL, Allen DB. Diabetes mellitus and exercise. Clin Sports Med 1992;11:403-18.

2 Skyler JS. Prevention and treatment of diabetes and its complications. Med Clin North Am 1998;82:665.

3 Expert committee on the diagnosis and classification of diabetes mellitus. Report of the expert committee on the diagnosis and classification of diabetes mellitus. Diabetes Care 1997;20:1183-97.

4 Diabetes control and complications trial research group. The effect of intensive treatment of diabetes on the development and progression of long-term complications in insulin-dependent diabetes mellitus. $N$ Engl $f$ Med 1993;329:977-86.

5 Wasserman DH, Abumrad NN. Physiological bases for the reatment of the physically active individual with diabetes. Sports Med 1989;7:376-92

6 Zinman B. Diabetes and exercise. Postgrad Med 1979;66:812.

7 Frid A, Ostman J, Linde B. Hypoglycaemia risk during exercise after intramuscular injection of insulin in the thigh of IDDM. Diabetes Care 1990;8:337-43.

8 Wasserman DH, Zinman B. Exercise in individuals with IDDM. Diabetes Care 1994;17:924-37.

9 Schneider SH, Vitug A, Ananthakrishnan R, et al. Impaired adrenergic response to prolonged exercise in type I diabetes. Metabolism 1991;40:1219-25.

10 Berger M, Assal JP, Jorgens V. Physical exercise in the diabetic. The importance of understanding endocrine and diabetic. The importance of understanding endocr

11 Nermoen I, Jorde R, Sager G, et al. Effects of exercise on hypoglycaemic responses in insulin-dependent diabetes mellitus. Diabete Metab 1998;24:131-6.

12 Kilgour RD, Williams PA. Diabetes affects blood pressure and heart rate responses during acute hypothermia. Acta Physiol Scand 1998;162:27-32.

13 Berg K. The insulin-dependent diabetic runner. Physician and Sportsmedicine 1979;7:71-9.

14 Tattersall RB. A force of magical activity: the introduction of insulin treatment in Britain 1922-1926. Diabet Med 1995; 12:739-55.

15 King P, Kong MF, Parkin H, et al. Well-being, cerebral function, and physical fatigue after nocturnal hypoglycemia in IDDM. Diabetes Care 1998;21:341-5.

16 Zinman B, Zuniga-Guajardo S, Kelly D. Comparison of the acute and long-term effects of exercise on glucose control in type I diabetes. Diabetes Care 1984;7:515-19.

17 Stratton R, Wilson DP, Endres RK. Acute glycemic effects of exercise in adolescents with insulin-dependent diabetes mellitus. Physician and Sportsmedicine 1988;16:150-7.

18 Dunstan DW, Puddey IB, Beilin LJ, et al. Effects of a shortterm circuit weight training program on glycaemic control in NIDDM. Diabetes Res Clin Pract 1998;40:53-61.

19 Huttunen NP, Lankela SL, Knip M, et al. Effect of once-aweek training program on physical fitness and metabolic control in children with IDDM. Diabetes Care 1989;12: 737-40

20 Perry TL, Mann JI, Lewis-Barned NJ, et al. Lifestyle intervention in people with insulin-dependent diabetes mellitus (IDDM). Eur f Clin Nutr 1997;51:757-63.

21 Rasmussen OW, Lauszus FF, Hermansen K. Effects of postprandial exercise on glycemic response in IDDM subjects: studies at constant insulinemia. Diabetes Care 1994;17:1203-5.

22 McDonald MJ. Post-exercise late-onset hypoglycaemia in insulin-dependent diabetic patients. Diabetes Care 1987;10: 584-8.

23 Jorgens V, Grusser M, Bott U, et al. Effective safe translation of intensified insulin therapy to general internal medicine departments. Diabetologia 1993;36:99-105.

24 Blackett PR. Child and adolescent athletes with diabetes. Physician and Sportsmedicine 1988;16:133-49.

25 Devlin JT, Ruderman N, eds. The health professional's guide to diabetes and exercise. Alexandria, VA: American Diabetes Association, 1995.

26 Koivisto VA, Felig P. Effects of leg exercise on insulin absorption in diabetic patients. N Engl F Med 1978;298:7783.

27 Salzsieder E, Fischer U, Stoewhas H. A model-based system for the individual prediction of metabolic responses to improve the therapy in type I diabetes. Horm Metab Res improve the therapy in

28 Trovati M, Carta Q, Cavalot F, et al. Continuous subcutaneous insulin infusion and postprandial exercise in tightly cous insulin infusion and postprandial exercise in tightly controlled type I (insulin-depe
Diabetes Care 1984;7:327-30.

29 Sonnenberg GE, Kemmer FW, Berger M. Exercise in type 1 (insulin-dependent) diabetic patients treated with continuous subcutaneous insulin infusion. Prevention of exercise induced hypoglycaemia. Diabetologia 1990;33:696-703.

30 Schiffrin A, Parikh S. Accommodating planned exercise in type I diabetic patients on intensive treatment. Diabetes Care 1985;8:337-42.

31 Edelmann E, Staudner V, Bachmann W. Exercise-induced hypoglycaemia and subcutaneous insulin infusion. Diabet Med 1986;3:526-31.

32 Anderson JH, Jr, Koivisto VA. Clinical studies on insulin lispro. Drugs of Today 1998;34(suppl C):37-50.

33 Minuk HL, Vranic M, Marliss EB. Glucoregulatory and metabolic response to exercise in obese noninsulindependent diabetes. Am $\mathcal{F}$ Physiol 1981;3:E458-64. 
34 Devlin JT, Hirshman M, Horton ED, et al. Enhanced peripheral and splanchnic insulin sensitivity in NIDDM peripheral and splanchnic insulin sensitivity in NIDDM
men after single bout of exercise. Diabetes 1987;36:434-9.

35 Koivisto VA, DeFronzo RA. Exercise in the treatment of type II diabetes. Acta Endocrinol 1984;105:107-11.

36 Riddle MC, Mcdaniel PA, Tive LA. Glipizide-GITS does increase the hypoglycemic effect of mild exercise during fasting NIDDM. Diabetes Care 1997;20:992-4

37 Gudat U, Bungert S, Kemmer F, et al. The blood glucose lowering effects of exercise and glibenclamide in patients with type 2 diabetes mellitus. Diabet Med 1998;15:194-8.

38 Kemmer FW. Prevention of hypoglycemia during exercise in type I diabetes. Diabetes Care 1992;15:1732-5.

39 De Fronzo RA, Goodman AM. The multi-centre metformin study group: efficacy of metformin in patients with non-insulin dependent diabetes. $N$ Engl f Med 1995;333 $541-9$.

40 Lohmann D, Liebold F, Heilmann W, et al. Diminished insulin and response in highly trained athletes. Metabolism 1978;27:521-4

41 Bjorntorp P, Fahlen M, Grimsby G, et al. Carbohydrate and fat metabolsim in middle-aged physically well trained men. Metabolism 1972;21:1037-44.

42 Bjorntorp P, Krotkiewski M. Exercise treatment in diabetes mellitus. Acta Med Scand 1985;217:3-7.

43 Horton ES. Exercise and decreased risk of NIDDM. $N$ Engl 7 Med 1991;325:196-8.

44 Koivisto VA, Jantunen M, Sane T, et al. Stimulation of prostacyclin synthesis by physical exercise in type I diabetes. Diabetes Care 1989:12:609-14.

45 Holloszy JO, Schultz J, Kusnierkiewicz J, et al. Effects of exercise on glucose tolerance and insulin resistance. Brie review and some preliminary results. Acta Med Scand 1986;220(suppl)

46 Segal KR, Edano A, Abalos A, et al. Effect of exercise training on insulin sensitivity and glucose metabolism in lean, obese, and diabetic men. $\mathcal{F}$ Appl Physiol 1991;71:2402-11.

47 Hughes VA, Fiatrone MA, Fielding RA. Exercise increases muscle GLUT-4 levels and insulin action in subjects with impaired glucose tolerance. Am f Physiol 1993;264:E855imp

48 Devlin JT. Effects of exercise in diabetes mellitus. F Fla Med Assoc 1986;73:602-3.

49 Mikenes KJ, Sonne B, Farrell PA, et al. Effect of physical exercise on sensitivity and responsiveness to insulin in humans. Am f Physiol 1988;254:E248-59.

50 Richter EA, Ploug T, Galbo H. Increased muscle glucose uptake after exercise. No need for insulin during exercise. Diabetes 1985;34:1041-8.

51 Ivy JL. Role of exercise training in the prevention and treatment of insulin resistance and non-insulin-dependent ment of insulin resistance and non-insulin-d
diabetes mellitus. Sports Med 1997;24:321-36.

52 Heath GW, Gavin JR, Hinderliter JM, et al. Effects of exercise and lack of exercise on glucose tolerance and insulin cise and lack of exercise on glucose toleranc
sensitivity. F Appl Physiol 1983;55:628-34.

53 King H, Kriska AM. Prevention of type II diabetes by physical training: epidemiological considerations and study methods. Diabetes Care 1992;15:1794-9.

54 King AC, Blair SN, Bild DE. Determinants of physical activity and interventions in adults. Med Sci Sports Exerc 1992;24(suppl 6):S221-36.

55 Oshida Y, Yamanouchi K, Hayamizu S, et al. Long-term mild jogging increases insulin action despite no influence on body mass index or VO2max. F Appl Physiol 1989;66: 2206-10.

56 Andersen $\mathrm{PH}$, Lund S, Schmitz O, et al. Increased insulin-stimulated glucose uptake in athletes: the fibre type composition of skeletal muscle. Acta Physiol fibre type composition of
Scand 1993;149:393-404.

57 Dela F, Ploug T, Handberg A, et al. Physical training increases muscle GLUT4 protein and mRNA in patients with NIDDM. Diabetes 1994;43:862-5.

58 Regensteiner JG, Shetterly SM, Mayer EJ, et al. Relationship betweeen habitual physical activity and insulin levels among non-diabetic men and women: the San Luis Valley Diabetes Study. Diabetes Care 1995;18:490-7.

59 Lipman RL, Raskin P, Love T. Glucose intolerance during decreased physical activity in man. Diabetes 1972;21:1017.

60 Physical acitivity and health. A report of the Surgeon General. Pittsburg: US Department of Health and Human Services, 1996 .

61 Helmrich SP, Ragland DR, Leung RW, et al. Physical activity and reduced occurrence of non-insulin-dependent
diabetes mellitus. N Engl f Med 1991;325:147-52.

62 Manson JE, Nathan DM, Krolewski AS, et al. A prospective study of exercise and incidence of diabetes among US male physicians. FAMA 1992;268:63-7.

63 Kaye SA, Folsom AR, Sprafka JM, et al. Increased incidence of diabetes mellitus in relation to abdominal adiposity in older women. F Clin Epidemiol 1991;44:329-34.

64 Eriksson KF, Lindgarde F. Prevention of Type 2 (noninsulin-dependent) diabetes mellitus by diet and physical exercise. The 6-year Malmo feasibility study. Diabetologia 1991;34:891-8.

65 Manson JE, Rimm EB, Stampfer MJ, et al. Physical activity and incidence of non-insulin-dependent diabetes mellitus in women. Lancet 1991;338:774-8.

66 Pan X, Li G, Hu Y. Effect of dietary and/or exercise intervention on incidence of diabetes in 530 subjects with impaired glucose tolerance from 1986-1992. Diabetologia 1995;34:891-8.
$67 \mathrm{NIH}$ consensus development panel on physical activity and ardiovascular health. Physical activity and cardiovascular health. $¥ A M A$ 1996;276:241-6.

68 Manson JE, Nathan DM, Krolewski AS, et al. Exercise and incidence of diabetes among U.S. male physicians. Ann Intern Med 1992;118(suppl 1).

69 Mayer-Davis EJD, Agostino R Jr, Karter AJ, et al. Intensity and amount of physical activity in relation to insulin ensitivity: the Insulin Resistance Atherosclerosis Study. FAMA 1998;279:669-74.

70 Fukimoto WY. A national multicentre study to learn whether type 2 diabetes can be prevented. The Diabetes Prevetion Program. Diabetes Care 1997;15:13-15.

71 Wing RR, Venditti E, Jakicic JM, et al. Lifestyle intervention in overweight individuals with a family history of diabetes. Diabetes Care 1998;21:350-9.

72 Bloomgarden ZT. Amercian Diabetes Association. Diabetes Care 1997;20:1913-17.

$73 \mathrm{Pan} \mathrm{X}, \mathrm{Li} \mathrm{G}, \mathrm{Hu} \mathrm{Y}$, et al. Effect of diet and exercise in preventing NIDDM in people with impaired glucose tolerance. Diabetes Care 1997;20:537-44.

74 Torjesen PA, Birkeland KI, Anderssen SA, et al. Lifestyle changes may reverse development of the insulin resistance syndrome. Diabetes Care 1997;20:26-31.

75 Eriksson KF, Lindgarde F. No excess 12-year mortality in men with impaired glucose tolerance who participated in the Malmo Preventive Trial with diet and exercise. Diabetologia 1998;41:1010-16.

76 Anonymous. Summary of the surgeon generals report addressing physical activity and health. Nutr Rev 1996;54: $280-4$.

77 Miller WJ, Sherman WM, Ivy JL. Effect of strength training on glucose tolerance and post-glucose insulin response. Med Sci Sports Exerc 1984;16:539-43.

78 Pate RR, Pratt M, Blair SN, et al. Physical activity and public health: a recommendation from the Centers for Disease Control and Prevention and the American College of Sports Medicine. $7 A M A$ 1995;273:402-7.

79 Zimmet PZ. Kelly West Lecture 1991. Challenges in diabetes epidemiology: from West to the rest. Diabetes Care 1992;15:232-52.

80 Reaven GM. Role of insulin resistance in human disease. Diabetes 1988;37:1595-607.

81 Hjermann I. The metabolic cardiovascular syndrome: syndrome X, Reaven's syndrome, insulin resistance syndrome, atherothrombogenic syndrome. 7 Cardiovasc Pharmacol 1992;20(suppl 8):S5-10.

82 Bierman EL. Atherogenesis in diabetes. Arterioscler Thromb 1992;12:647-56.

83 Paffenbarger RS, Jr, Hyde RT. Exercise as protection against heart attack. N Engl $\mathcal{F}$ Med 1980;302:1026-7.

84 Paffenbarger RS Jr, Hyde RT, Wing AL, et al. Physical activity, all-cause mortality, and longevity of college alumni. $N$ Engl F Med 1986;314:605-13.

85 Leon AS. Effects of exercise conditioning on physiologic precursors of coronary heart disease. 7 Cardpulm Rehabil

86 Blair SN, Kohl HW III, Paffenbarger RS Jr, et al. Physical fitness and all-cause mortality: a prospective study of healthy men and women. $\mathcal{F} A M A$ 1989;262:2395-401.

87 Sheps SG, Dart RA. New guidelines for prevention, detection, evaluation, and treatment of hypertension: joint national committee VI. Chest 1998;113:263-5.

88 Blair SN, Kohl IH, Barlow CE, et al. Changes in physical fitness and all-cause mortality: a prospective study of healthy and unhealthy men. $₹ A M A$ 1995;273:1093-8.

89 Anonymous. ADA/ACSM: diabetes mellitus and exercise. Joint position paper. Med Sci Sports Exerc 1997;29:1-6.

90 Blair SN, Powell KE, Bazzarre TL, et al. Physical inactivity: workshop V. Circulation 1993;88:1402-5.

91 Klesges RC, Klesges LM, Haddock CK, et al. Longitudinal analysis of the impact of dietary intake and physical activity. Am f Clin Nutr 1992;55:818-22.

92 Weyer C, Linkeschowa R, Heise T, et al. Implications of the traditional and new ACSM physical activity recommendations on weight reduction in dietary treated obese subjects. Int $\mathcal{F}$ Obes 1998;22:1071-8.

93 Eriksson KF, Lindgarde F. No excess 12-year mortality in men with impaired glucose tolerance who participated in the Malmo Preventive Trial with diet and exercise. Diabetologia 1998;41:1010-16.

94 Wallberg-Henriksson H, Gunnarsson R, Henriksson J, et al. Increased peripheral insulin sensitivity and muscle mitochondrial enzymes but unchanged blood glucose control in type I diabetics after physical training. Diabetes 1982;31: $1044-50$

95 King AC, Haskell WL, Taylor CB, et al. Home-based exercise training in healthy older men and women. $\mathfrak{F} A M A$ 1991;266:1535-42.

96 Maehlum S, Dahl-Jorgensen K, Meen HD. Physical activity and diabetes mellitus. Tidsskr Norsk Laegeforen 1980;100 $840-4$

97 Noble BJ. Preface to the symposium on recent advances in the study and clinical use of perceived exertion. Med $\mathrm{Sci}$ Sports Exerc 1982;14:377-81.

98 Fox KR. Promoting physical activity in people with diabetes. Practical Diabetes International 1998;15:146-50.

99 Mittleman MA, Maclure M, Tofler GH, et al. Triggering of acute myocardial infarction by heavy physical exertion. $N$ Engl f Med 1993;329:1677-83.

100 Dahlquist G, Aperia A, Carlsson L, et al. Effect of metabolic control and duration on exercise-induced albuminuria in diabetic teenagers. Acta Paediatr Scand 1983;72:895-902. 
101 United Kingdom prospective diabetes study group. UK prospective diabetes study X: urinary albumin excretion
over 3 years in diet-treated type 2 (non-insulin-dependent) diabetic patients, and association with hypertension, hyperdiabetic patients, and association with hypertension, hyper-
glycaemia and hypertriglyceridaemia. Diabetologia 1993;36: glycaemia

102 Matsuoka K, Nakao T, Atsumi Y, et al. Exercise regime for diabetics with diabetic nephropathy. $f$ Diabetes Complications 1991;5:98-100.

103 Sacco RL, Gan R, Boden-Albala B, et al. Leisure-time physical activity and ischemic stroke risk: the Northern Manhattan stroke study. Stroke 1998;29:380-7.

104 Goldstein D. Clinical applications for exercise. $7 A M A$ 1989;17:83-93.

105 Vered Z, Battler A, Segal P, et al. Exercise-induced left ventricular dysfunction in young men with asymptomatic diabetes mellitus (diabetic cardiomyopathy). Am $\mathcal{f}$ Cardiol 1984;54:633-7.

106 Margolis JR, Kannel WB, Feinlab M. Clinical features of unrecognised myocardial infarction: silent and symptomatic. Eighteen year follow up: The Framingham Study. Am 7 Cardiol 1973;32:11-17.

107 Bruce RA, Hossack KF, Doroun TA, et al. Enhanced risk assessment for primary coronary heart disease events maximal exercise testing: 10 years' experience of Seattle Heart Watch. F Am Coll Cardiol 1983;2:565-75

108 Rubler S, Gerber D, Reitano J, et al. Predictive value of clinical and exercise variables for detection of coronary artery disease in men with diabetes mellitus. Am $\mathcal{F}$ Cardiol 1987;59:1310-13.

109 Schneider SH, Amorosa LF, Khachadurian AK, et al. Studies on the mechanism of improved glucose control during regular exercise in type 2 (non-insulin-dependent) diabetes. Diabetologia 1984;26:355-60.

110 Regensteiner JG, Sippel J, McFarling ET, et al. Effects of non-insulin-dependent diabetes on oxygen consumption during treadmill execise. Med Sci Sports Exerc 1995;27: during trea

111 American Diabetes Association. Concensus statment: detection and management of lipid disorders in diabetes. detection and management of lipid diso
Diabetes Care 1996;19(suppl 1):S96-102.

112 Krolewski AS, Kosinski EJ, Warram JH. Magnitude and determinants of coronary artery disease in juvenile-onset, insulin-dependent diabetes mellitus. Am f Cardiol 1987;59: $750-5$.

113 Krolewski AS, Warram JH, Valsania P. Evolving natural history of coronary artery disease in diabetes mellitus: the Finnish stduies. Am f Med 1991;90(suppl 2A):56S-61S.

114 Panzram G. Mortality and survival in type 2 (non insulindependent diabetes) diabetes mellitus. Diabetologia 1987; 30:123-31.

115 Moss SE, Klein R, Klein BE. Cause-specific mortality in a population based study of diabetes. Am f Public Health 1991;81:1158-62.

116 Naka M, Hiramatsu K, Aizawa T, et al. Silent myocardial ischemia in patients with non-insulin-dependent diabetes mellitus as judged by treadmill exercise testing and coronary angiography. Am Heart f 1992;123:46-53.

117 Estacio RO, Regensteiner JG, Wolfel EE, et al. The association between diabetic complications and exercise capacity ation between diabetic complications and exercise

118 Nesto RW, Phillips RT, Kett KG, et al. Angina and exertional myocardial ischemia in diabetic and nondiabetic patients: assessment by exercise thallium scintigraphy. Ann Intern Med 1988;108:170-5.

119 Langer A, Freeman MR, Josse RG, et al. Detection of silent myocardial ischemia in diabetes mellitus. Am $\mathcal{f}$ Cardio 1991;67:1073-8.

120 Kannel WB. Lipids, diabetes, and coronary heart disease: insights from the Framingham study. Am Heart $f$ 1985;110:1100-7.

121 Hypertension in diabetes study group. HDS 1: prevalence of hypertension in newly presenting type 2 diabetic patients and the association with risk factors for cardio-vascular and diabetic complications. F Hypertens 1993;11:309-17.

122 United Kingdom prospective diabetes study group. UK prospective diabetes study 23: risk factors for coronary artery disease in non-insulin dependent diabetes. BM7 1998:316:823-8.

123 Hypertension in diabetes study group. HDS 2: Increased risk of cardio-vascular complications in hypertensive type 2 diabetic patients. F Hypertens 1993;11:319-25.

124 United Kingdom prospective diabetes study group. UK prospective diabetes study 30 : diabetic retinopathy at diagnosis of type 2 diabetes and associated risk factors. Arch Ophthalmol 1998;116:297-303.

125 Schneider SH, Morgado A. Effects of fitness and physical training on carbohydrate metabolism and associated cardiovascular risk factors in patients with diabetes. Diabetes Reviews 1995;3:378-407.

126 Blackburn H. Physical activity and hypertension. Fournal of Clinical Hypertension 1986;2:154-62.

127 Butler RM, Goldberg L. Exercise and prevention of coronary heart disease. Prim Care 1989;16:99-114.

128 Davies MD. Diabetic retinopathy: a clinical overview. Diabetes Care 1992;15:1844-74.

129 Albert SG, Gomez CR, Russell S, et al. Cerebral and ophthalmic artery hemodynamic responses in diabetes mellitus. Diabetes Care 1993;16:476-82.

130 Margonato A, Gerundini P, Vicedomini G, et al. Abnormal cardiovascular response to exercise in young asymptomatic diabetic patients with retinopathy. Am Heart $\mathcal{F}$ 1986;112: $554-60$

131 Greene DA, Pfeifer MA. In: Olefsky JM, Sherwin RS, eds. Diabetes mellitus. New York: Churchill Livingstone, 1985.

132 Young R, Ewing D, Campbell B. Nerve function and metabolic control in diabetes. Diabetes 1983;32:142-7.

133 Karlefors T. Exercise test in male diabetes. Acta Med Scand 1966;180(suppl 449):3-8.

134 Hilsted J, Galbo H, Christensen NJ. Impaired responses of catecholamines, growth hormone, and cortisol to graded exercise in diabetic autonomic neuropathy. Diabetes 1980; 29:257-62.

135 Hilsted J, Galbo H, Christensen NJ, et al. Haemodynamic changes during graded exercise in patients with diabetic autonomic neuropathy. Diabetologia 1982;22:318-23.

136 Rubler S, Chu DA, Bruzzone CL. Blood pressure and heart rate responses during 24-hour ambulatory monitoring and exercise in men with diabetes mellitus. Am f Cardiol 1985;55:801-6.

137 Ewing D, Campbell I, Clarke B. The natural history of diabetic autonomic neuropathy. Quarterly Medical fournal 1980;49:95-108.

138 Ewing D, Campbell I, Clarke B. Heart rate changes in diabetes mellitus. Lancet 1981;1:183-6.

139 Kahn JK, Sisson JC, Vinik AI. QT interval prolongation and sudden cardiac death in diabetic autonomic neuropathy. $f$ Clin Endocrinol Metab 1987;64:751-4.

140 Ferrari AU. Modulation of parasympathetic and baroreceptor control of heart rate. Cardioscience 1993;4:9-13.

141 Broadstone VL, Roy T, Self M, et al. Cardiovascular autonomic dysfunction: diagnosis and prognosis. Diabet Med 991;8(symposium):S88-93.

142 Sundkvist G, Bergstrom B, Manhem P, et al. Blunted epinephrine response following exercise in autonomic neuropathy. Diabetologia 1995;38.

143 Conti SF, Chaytor ER. Steps to healthy feet for active people with diabetes. FAMA 1995;23:71-2.

144 Chantelau E, Kushner T, Spraul M. How effective is cushioned therapeutic footwear in protecting diabetic feet? Diabetes Med 1990; 7:355-9.

145 Kastenbauer T, Sokol G, Auinger M, et al. Running shoes for the relief of plantar pressure in diabetic patients. Diabet Med 1998;15:518-22.

146 Norton K, Olds T, Bowes D, et al. Applying the sports medicine Australia pre-exercise screening procedures: who will be excluded? F Sci Med Sport 1998;1:38-51.

147 Goodyear LJ. Exercise, glucose transport, and insulin sensitivity. Aппи Rev Med 1998;49:235-61.

148 Brooks GA, Fahey TD, White TP. Exercise physiology. 2nd ed. Mount View, CA: Mayfield Publishing Co., 1996:56.

True or false?

1 Glucose uptake:

(a) Training permanently improves insulin sensitivity in non-insulin dependent diabetes mellitus (NIDDM).

(b) Exercise can augment insulin stimulated glucose uptake in diabetes.

(c) Insulin increases hepatic glucose production.

(d) Insulin increases muscle and liver glycogen production.

(e) In type 2 diabetes, hypoglycaemia occurs frequently, owing to enhanced insulin sensitivity.

2 Hypoglycaemia:

(a) Symptoms are likely to be masked by moderate intensity exercise.

(b) 1-5 g of carbohydrate at the onset of symptoms will alleviate most hypoglycaemic attacks.

(c) Diving is contraindicated in diabetes.

(d) Delayed onset hypoglycaemia occurs up to four hours after activity.

(e) Intensive education can reduce the risk of hypoglycaemia. 
3 Insulin dependent diabetes mellitus (IDDM) is associated with:

(a) Increased risk of retinal detachment during exercise.

(b) Increased incidence of silent myocardial ischaemia.

(c) A shortened QTc (corrected) interval on electrocardiograph testing.

(d) A need for a reduced carbohydrate diet to prevent hyperglycaemia during exercise

(e) Resistance training is contraindicated.

4 Exercise programmes:

(a) Gentle "warm up" increases the risk of hypoglycaemia.

(b) Vigorous activity is always contraindicated in IDDM and NIDDM.

(c) Motivation and compliance are low in NIDDM.

(d) Can reduce the relative risk of developing NIDDM in impaired glucose tolerance by as much as $60 \%$.

(e) Are contraindicated in those with sensory neuropathy.

(Answers p 222.)

\section{How I treat: return to sport after post-viral fatigue}

Heavy training loads may predispose elite athletes to an increased risk of viral upper respiratory tract infections. ${ }^{1}$ These infections are usually mild with few complications other than being a short term impediment to the attainment of training goals. Occasionally, an upper respiratory tract infection is complicated by persisting postviral fatigue, which can limit full training for many months. In such cases, "over vigorous" exercise may sometimes prolong the fatigue and delay return to sport. The challenge for the sports doctor is to provide appropriate and safe recommendations, to facilitate the earliest return to full training.

Initially, if generalised symptoms and signs are present, exercise is stopped and is not permitted until all such symptoms have disappeared (with the exception of some increase in the need for sleep). An examination is performed to exclude complications or contraindications to sporting activity, such as fever, hepatosplenomegaly, or significant tachycardia (that is-resting pulse $>80$ beats per minute or raised by more than $20 \%$ above normal). In cases of infectious mononucleosis, contact sport is not advised for four weeks owing to the potential risk of splenic rupture.

Recommendations for initial exercise are for 20-30 minutes (maximum) of aerobic exercise, with an intensity not exceeding $65 \%$ of maximum heart rate. The exercise can be repeated the next day, but only if there has been no recurrence of any symptoms (such as fatigue, myalgia, headache, lassitude, fever, sore throat) or if there is no tender lymphadenopathy and the resting heart rate has not risen by more than $20 \%$ from the previous day. If symptoms recur, exercise is not repeated until the symptoms have resolved fully. Once the athlete is able to train daily at this intensity and duration for several consecutive days the training frequency is increased to twice daily and should coincide with usual training sessions. When this can be achieved comfortably, the length of the sessions is increased in 10-15 minute increments until full training duration and frequency are reached. The last component of exercise to increase is the intensity of training, and this is also increased gradually (table 1).

Table 1 Summary of guidelines for return to exercise after a viral illness

\begin{tabular}{lll}
\hline $\begin{array}{l}\text { Exercise } \\
\text { component }\end{array}$ & Initial activity & $\begin{array}{l}\text { Order in which to } \\
\text { increase }\end{array}$ \\
\hline Frequency & Maximum of once daily & 1 \\
Duration & $20-30$ minutes aerobic & 2 \\
Intensity & $65 \% \mathrm{HR}$ & 3
\end{tabular}

Monitor: fatigue, sore throat, fever, myalgia, lymphadenopathy, resting heart rate.

Throughout the return to sport, the athlete is encouraged to keep a record of symptoms, heart rates during rest and recovery from exercise bouts, and the frequency, duration, and intensity of exercise. The athlete should be advised to see the sports doctor regularly (at least weekly) and should be aware that some relapses are inevitable, and that the exercising heart rate may be abnormally raised even at low work rates. If symptoms recur, the athlete is instructed to rest until these have resolved and then restart exercise at the previously attained level.

MARK YOUNG

Registrar in Sports Medicine (ACSP) Australian Institute of Sport Canberra, Australia

1 Nieman DC, Johansen LM, Lee JW, et al. Infectious epi-
sodes in runners before and after the Los Angeles Marathon. $\mathcal{F}$ Sports Med Phys Fitness 1990;30:316-18. 